\title{
Trend of tuberculosis and performance evaluation of new sputum positive tuberculosis from Satara district, India
}

\author{
Mohite RV ${ }^{1}$, Mohite VR², Ganganahalli PG ${ }^{3}$, Lale SV ${ }^{4}$ \\ ${ }^{1}$ Assistant Professor, Dept of Community Medicine, Krishna Institute of Medical Sciences University, Karad, India, ${ }^{2}$ Professor and Principal, \\ Krishna Institute of Nursing Sciences, Krishna Institute of Medical Sciences University, Karad, India, ${ }^{3}$ Assistant Professor, Dept of Community \\ Medicine, Krishna Institute of Medical Sciences University, Karad, India, ${ }^{4}$ District Tuberculosis Officer, Satara District, Government of \\ Maharashtra, India
}

\section{A B S T R A C T}

Background: Tuberculosis (TB) has remained a major public health threat worldwide and considering this, Govt. of India declared TB as notifiable disease in year 2012. Objectives: To assess the trend of TB in Satara district, India and to evaluate outcome of new sputum positive TB cases registered under district Revised National Tuberculosis Control Programme (RNTCP). Materials and Methods: A retrospective record based cross-sectional study was conducted in District Tuberculosis Centre (DTC), Satara district, Maharashtra, India during March 2013. All Registered TB cases under DTC from the year 2002 to 2012 were included as study subjects. The district RNTCP records since the year 2002-2012, for all TB cases were viewed and analyzed by investigator according to RNTCP outcome evaluation indicators. The trend of TB was statistically analyzed for the period of eleven years by using chi-square trend test. Results: Annual the total TB case detection rate was 117.94/lakh for year 2002 which decreased to 98.30/lakh for year 2012. The proportions of pulmonary TB cases decreased from $92.23 \%$ to $81.0 \%$ since year 2002 to 2012 whereas proportions of HIVreactive TB cases increased from $3.11 \%$ to $25.3 \%$ since year 2009 to 2011 . Proportions of male TB cases were almost the double of females; however child TB cases increased continuously with maximum TB cases belonged to pulmonary type. The proportional trend of New Sputum Positive (NSP) cases showed periodic fluctuations ranging from 34\% to $50 \%$ since year 2002 to 2012 . The performance of outcome evaluation indicators of NSP cases during evaluation period as viz., cure rate ranging from $79.91 \%$ to $87.02 \%$ with periodic fluctuations, sputum conversion rate continuously increased from $78.5 \%$ to $93.5 \%$, treatment success rate ranging from $82.7 \%$ to $90 \%$ with apparent difference, whereas defaulter rate decreased from $7.5 \%$ to $3.8 \%$ by year 2011 , treatment failure rate continuously decreased to $2.1 \%$ whereas Death rate ranging from $5.2 \%$ to $10.4 \%$. The proportional trends of outcome evaluation indicators of NSP-TB cases showed statistically significant difference over period of year 2002 to 2012. Conclusion: Data indicates that TB is still big problem in rural area of western Maharashtra, India and need to strengthen the awareness programme about TB and involvement of private health sector to control the burden of TB.

Key words: Tuberculosis, RNTCP, HIV, Evaluation

\section{INTRODUCTION}

Tuberculosis (TB) is a disease with devastating social, economic cost and has remained a major public health
Access this article online

Website:

http://nepjol.info/index.php/AJMS

DOI: $10.3126 / a j m s . v 6 i 4.11112$

Address for Correspondence:

Dr. Mohite R.V.(MD,PSM), Assistant Professor, Dept of Community Medicine, Krishna Institute of Medical Sciences University, Karad, India E-mail: rajsinhmohite124@gmail.com 
that the toll of new cases of tuberculosis was 8.6 million and mortality of 1.3 million. ${ }^{1}$ It is also estimated that by year 2020, the global burden of TB may reach beyond one billion and of which more than $80 \%$ disease burden could be from the poor resourced countries. ${ }^{2,3}$

TB remains a major public health problem in India and accounts for one- fourth of the estimated global incident TB cases in year 2010. ${ }^{4,5}$ Every year in the India nearly 1.5 to 1.8 million people develops TB and approximately 8 lakh is the incidence of sputum smear-positive cases. Tuberculosis is captain of deaths in India. Nearly 2.8 lakh people die of TB every year ${ }^{6}$ mainly due to poverty, illiteracy, malnutrition, inadequate health care services, negative attitude of community, traditional medical practices and burden of HIV-AIDS infection.

Recently, the burden of resistant TB is again emerging big challenge to India and by considering this Govt. of India announces TB as a notifiable disease in year 2012. Annual risk of tuberculosis infection, the most important epidemiological indicators of disease burden in a community. Single open case of pulmonary tuberculosis can infect $10-15$ persons in a year, so government mainly emphasis on early detection of new smear positive cases and immediately put them on Directly Observed Treatment Short (DOTS) course therapy. The vision of "TB free India" is adopted by Govt of India in revised RNTCP policy in $12^{\text {th }}$ five year plan 2012-17 with aim of "Universal access" for quality diagnosis and treatment for all TB patients.

Keeping this in view, the present study aimed to assess the trend of annual case detection of TB in Satara district, India and to assess the outcome of new sputum positive TB cases under district RNTCP.

\section{MATERIALS AND METHODS}

A retrospective record based cross-sectional study was conducted in District Tuberculosis Centre (DTC), Satara district, Maharashtra, India during March 2013. All Registered TB cases under DTC from year 2002 to 2012 were included as study subjects. The data collection was started after obtained written permission from District Tuberculosis Officer (DTO) \& District Health Officer (DHO). The RNTCP records for year 2002 to 2012, i.e. the 11- year period, for all TB cases were analyzed by investigator according to RNTCP outcome evaluation indicators as follows. ${ }^{8}$

\section{Annual case detection rate}

It is the percentage of new confirmed TB cases per one lakh population occurring during one year.

\section{Cure rate}

Percentage of patients initially sputum smear- positive who has completed treatment and had negative sputum smears, on two occasions, one of which was at the end of treatment.

\section{Sputum conversion rate}

Percentage of sputum smear positive converted to smear negative at the end of intensive phase per total number of sputum smear positive patients initiated on treatment.

\section{Treatment success rate}

The percentage of new, registered smear positive infectious cases that were cured or in which a full course of treatment was completed.

\section{Default rate}

Percentage of patients who has not taken anti-TB drugs for 2 months or more consecutively after starting treatment.

Treatment failure rate

Percentage of sputum smear positive cases after 5 months of treatment per total number of sputum smear positive patients initiated on treatment.

\section{Death rate}

Percentage of patients who were died during the course of treatment regardless of cause.

The data was compiled and entered into MS Excel 2007. The trend of annual case detection rate, gender and TB, outcome of New Sputum Positive cases under DOTS etc were analyzed. The trend was statistically analyzed for 2002-2012 by using chi-square test for trend. Trend was considered significant if $\mathrm{p}$ value is less than 0.05 .

\section{Infrastructure DTC, Satara}

The DTC coverage includes 11 blocks and 1750 villages. Public health care services are rendered by one District Hospital, seventeen Rural Hospitals, seventy one Primary Health Centres and four hundred Sub-Centres. One Private Medical College also provides DOTS therapy to TB patients. DTC is run by one DTO, three Medical Officers, Laboratory Technicians(14), Senior Treatment Supervisors(10) Senior TB Lab Supervisors(10), Multi Purpose Health Supervisors (1) Multi Purpose Health Assistants (2) X-ray tech,(1) TBHV(2).

\section{RESULTS}

A total of 40,998 TB cases were registered under Satara DTC during the year 2002 to 2012.

Annual case detection rate of TB was 117.94/lakh for 2002. It was increased to 151.14/lakh for 2006 and then decreased to 98.28 /lakh for 2012, with total no of TB cases 
were decreased to 2991 for 2012. The trend of Annual case detection rate was studied, which was linear and was statistically significant $(\chi 2$ trend $=313.3, \mathrm{p}<0.0001 *)$ (Figure 1).

Among total TB cases, proportion of pulmonary cases showed a declining trend from $92.23 \%$ to $81 \%$ since 2002 to 2012. However, proportion of extra-pulmonary cases showed steadily upward trend from $7.76 \%$ to $18.45 \%$. The proportion of TB-HIV cases (lab confirmed) increased from $3.11 \%$ to $25.31 \%$ since 2009 to 2011 but decreased to $9.62 \%$. for 2012. The trend of pulmonary and extra-pulmonary TB cases since 2002 to 2012 shows statistically significant difference $\left(\chi 2\right.$ trend $\left.=496.3, \mathrm{p}<0.0001^{*}\right)$ (Table 1$)$.

Among total TB cases, proportion of males were declined from $76.43 \%$ to $52.23 \%$ since 2002 to 2009 but again increased to $56.16 \%$ for 2012 . The proportion of females showed upward trend from $22.84 \%$ to $37.54 \%$ with periodic fluctuating during study period. Proportion of child cases were increased from $0.71 \%$ to $8.66 \%$ since 2002 to 2011 but for 2012 decreased to 6.28\%. The trend of male, female and child cases among total TB cases was

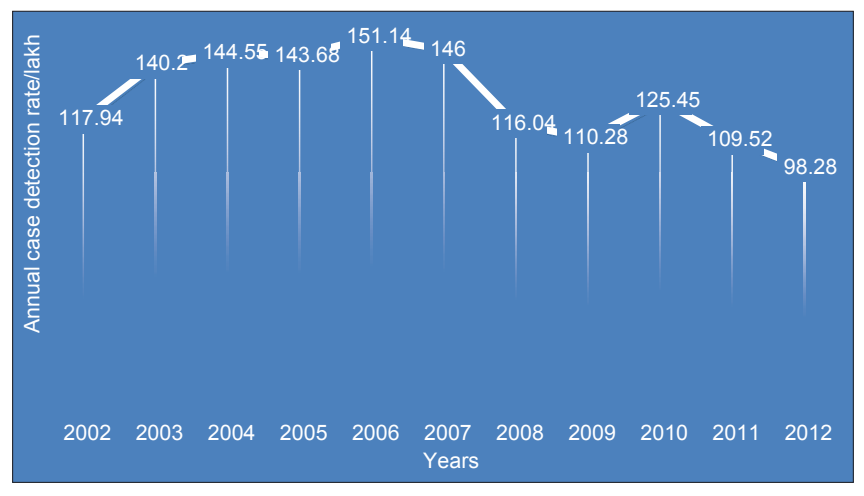

Figure 1: Annual Tuberculosis case detection rate. $\chi 2$ trend $=313.3$, $\mathrm{p}<0.0001^{*}\left({ }^{*}=\right.$ significant statistical trend at $95 \%$ confidence interval)

\begin{tabular}{|c|c|c|c|}
\hline Year & $\begin{array}{c}\text { Annual total } \\
\text { pulmonary } \\
\text { TB cases, }(\%)\end{array}$ & $\begin{array}{c}\text { Annual total } \\
\text { extra- pulmonary } \\
\text { TB cases }(\%)\end{array}$ & $\begin{array}{c}\text { Annual } \\
\text { total HIV-TB } \\
\text { cases (\%) }\end{array}$ \\
\hline 2002 & $3077,(92.23)$ & $259,(7.76)$ & Nil \\
\hline 2003 & $3681,(92.18)$ & $312,(7.81)$ & Nil \\
\hline 2004 & $3756,(90.61)$ & $389,(9.38)$ & Nil \\
\hline 2005 & $3632,(87.56)$ & $516,(12.43)$ & Nil \\
\hline 2006 & $3847,(87.61)$ & $544,(12.38)$ & Nil \\
\hline 2007 & $3709,(86.82)$ & $563,(13.17)$ & Nil \\
\hline 2008 & 2901, (84.87) & 517, (15.12) & Nil \\
\hline 2009 & 2655, (81.19) & 615, (18.80) & 102, (3.11) \\
\hline 2010 & $3035,(81.06)$ & $709,(18.93)$ & 509, (13.59) \\
\hline 2011 & $2746,(83.46)$ & $554,(16.83)$ & $833,(25.31)$ \\
\hline 2012 & $2439,(81.54)$ & $552,(18.45)$ & $288,(9.62)$ \\
\hline
\end{tabular}

studied, which was linear and showed significant difference $\left(\chi 2\right.$ trend $\left.=225.2, \mathrm{p}<0.0001^{*}\right)($ Table 2$)$.

Proportions of pulmonary TB cases in male and female gender were declined from $94.86 \%$ to $83.86 \%$ and $83.20 \%$ to $74.97 \%$ respectively for period of 11 years. However, proportions of extra-pulmonary TB cases were showed upward trend from $5.13 \%$ to $17.63 \%$ and $10.05 \%$ to $25.03 \%$ respectively. The trend of male and female cases for pulmonary and extra-pulmonary TB was studied and was statistically significant $\left(@ \chi^{2}\right.$ trend $=314.7, \mathrm{p}<0.0001 *$, $\# \chi^{2}$ trend $\left.=204.2, \mathrm{p}<0.0001^{*}\right)$ (Table 3).

Since year 2002 to 2007, all child TB cases were belonged to pulmonary type only but from year 2008 onwards, the proportions of pulmonary TB cases decreased to $85.10 \%$ whereas extra-pulmonary increased to $14.89 \%$ for 2012 . The trend of child TB cases among pulmonary and extra-pulmonary depicts statically significant difference $\left(\chi^{2}\right.$ trend $\left.=11.3, \mathrm{p}<0.0007^{*}\right)($ Table 4$)$.

Among total pulmonary TB cases, maximum, 2182 NSP cases were reported for 2004 whereas maximum, 2224

\begin{tabular}{|c|c|c|c|}
\hline Year & $\begin{array}{c}\text { Annual total } \\
\text { male TB } \\
\text { cases, }(\%)\end{array}$ & $\begin{array}{c}\text { Annual total } \\
\text { female TB } \\
\text { cases, }(\%)\end{array}$ & $\begin{array}{c}\text { Annual total } \\
\text { child TB } \\
\text { cases, }(\%)\end{array}$ \\
\hline 2002 & $2550,(76.43)$ & $762,(22.84)$ & $24,(0.71)$ \\
\hline 2003 & $2611,(65.38)$ & $1353,(33.88)$ & $29,(0.72)$ \\
\hline 2004 & $2648,(63.88)$ & $1474,(35.56)$ & $23,(0.55)$ \\
\hline 2005 & $2528,(60.94)$ & $1579,(38.06)$ & $41,(0.98)$ \\
\hline 2006 & $2857,(65.04)$ & $1523,(34.68)$ & $11,(0.25)$ \\
\hline 2007 & $2632,(61.61)$ & $1610,(37.68)$ & $30,(0.70)$ \\
\hline 2008 & $1936,(56.64)$ & $1276,(37.33)$ & $206,(6.02)$ \\
\hline 2009 & $1708,(52.23)$ & $1307,(39.96)$ & $255,(7.79)$ \\
\hline 2010 & $2172,(58.01)$ & $1312,(35.04)$ & $260,(6.94)$ \\
\hline 2011 & $1760,(53.49)$ & $1245,(37.84)$ & $285,(8.66)$ \\
\hline 2012 & $1680,(56.16)$ & $1123,(37.54)$ & $188,(6.28)$ \\
\hline
\end{tabular}

\begin{tabular}{|c|c|c|c|c|}
\hline \multirow[t]{2}{*}{ Year } & \multicolumn{2}{|c|}{ Pulmonary TB cases } & \multicolumn{2}{|c|}{ Extra-pulmonary TB cases } \\
\hline & Male (\%)@ & Female (\%) ${ }^{\#}$ & Male, (\%) & Female, (\%) \\
\hline 2002 & $2419,(94.86)$ & $634,(83.20)$ & $131,(5.13)$ & $128,(16.79)$ \\
\hline 2003 & 2436, (93.29) & $1217,(89.94)$ & $175,(6.70)$ & 136, (10.05) \\
\hline 2004 & 2383, (90.10) & $1290,(87.51)$ & $265,(10.00)$ & $184,(12.48)$ \\
\hline 2005 & 2262, (89.47) & $1327,(84.04)$ & $266,(10.52)$ & $252,(15.95)$ \\
\hline 2006 & $2539,(88.86)$ & $1298,(85.22)$ & $318,(11.13)$ & $225,(14.77)$ \\
\hline 2007 & $2329,(88.48)$ & $1350,(83.85)$ & $303,(11.51)$ & $260,(16.14)$ \\
\hline 2008 & $1669,(86.20)$ & $1026,(80.40)$ & $267,(13.79)$ & $250,(19.59)$ \\
\hline 2009 & $1439,(84.25)$ & $958,(73.29)$ & $269,(15.74)$ & $349,(26.70)$ \\
\hline 2010 & $1789,(82.36)$ & $986,(75.15)$ & $383,(17.63)$ & $326,(24.84)$ \\
\hline 2011 & $1489,(84.60)$ & $962,(77.26)$ & $271,(15.39)$ & $283,(22.73)$ \\
\hline 2012 & $1409,(83.86)$ & 842, (74.97) & $271,(17.63)$ & $281,(25.03)$ \\
\hline
\end{tabular}


NSN cases were found for 2006. The proportion of NSP cases ranging from $41.3 \%$ to $58.1 \%$ with maximum and minimum cases reported in year 2006 and 2009 respectively. The trend of NSN cases showed periodic fluctuations over 11 years of study period with maximum and minimum proportion reported for $2009 \& 2004$ respectively. The trend of NSP and NSN was studied, and was statistically significant $\left(\chi^{2}\right.$ trend $\left.=290.53, \mathrm{p}<0.0001^{*}\right)$ (Figure 2).

Cure rate of NSP cases was in the range of $79.6 \%$ to $87 \%$ from 2002 to 2012 and was maximum in 2005 and minimum in 2009 with periodic upward and downward trend. Trend of sputum conversion rate was steadily showed upward trend from $78.5 \%$ to $93.5 \%$. Treatment success rate was in a range of $82.7 \%$ to $90.3 \%$ and trend was almost stable during study period (Figure 3.1), however defaulter rate was decreased from $7.5 \%$ to $2.8 \%$ since 2002 to 2010 but again increased to $4.7 \%$ for 2012 . Treatment failure rate was continuously decreased from $6.2 \%$ to $2.1 \%$ over period of 11 years. From 2002 to 2012, death rate among NSP cases was in a range of $5.2 \%$ to $10.4 \%$, and was maximum in 2009 and minimum in 2007 with period little fluctuation (Figure 3.2).

Trend of cure rate, treatment success rate, treatment completion rate, sputum conversion rate, defaulter rate,

\begin{tabular}{lcc}
\multicolumn{3}{l}{ Table 4: Trend of child tuberculosis } \\
\hline Year & $\begin{array}{c}\text { Pulmonary } \\
\text { TB cases, (\%) }\end{array}$ & $\begin{array}{c}\text { Extra-pulmonary } \\
\text { TB cases, (\%) }\end{array}$ \\
\hline 2002 & $24,(100.00)$ & $0,(0.00)$ \\
2003 & $29,(100.00)$ & $0,(0.00)$ \\
2004 & $23,(100.00)$ & $0,(0.00)$ \\
2005 & $41,(100.00)$ & $0,(0.00)$ \\
2006 & $11,(100.00)$ & $0,(0.00)$ \\
2007 & $30,(100.00)$ & $0,(0.00)$ \\
2008 & $186,(90.29)$ & $20,(9.70)$ \\
2009 & $211,(82.74)$ & $44,(17.25)$ \\
2010 & $238,(91.53)$ & $22,(8.46)$ \\
2011 & $262,(91.92)$ & $23,(8.07)$ \\
2012 & $160,(85.10)$ & $28,(14.89)$ \\
\hline$\chi^{2}$ trend $=11.3, p<0.0007^{*}$ &
\end{tabular}

failure rate and death rate of NSP- TB cases under DOTS strategy shows significant statistical trend over study period $(\mathrm{p}<0.05)$ (Table 5, Figures 1 and 2).

\section{DISCUSSION}

The present record based evaluation study conducted in Satara district, India since year 2002 to 2012 has been shown the upward trend of TB from year 2002 to 2006 but thereafter linear downward by 2012. Similar findings have also been reported by Govt. of India ${ }^{9}$ i.e. from $83 / \mathrm{lakh}$ to $116 / \mathrm{lakh}$ for period 1996 to 2004 then downward to 100/lakh by 2011 . However, TB reported from Italy ${ }^{10}$ was $17.3 /$ lakh for year 1996 and showed further declined trend. The high difference in incidence of TB was mainly due to lack of adequate infrastructure, population explosion and poverty.

Proportions of pulmonary TB cases decreased from $92.23 \%$ to $81 \%$, whereas extra-pulmonary increased from $7.76 \%$ to $18.45 \%$. A similar finding also reported from South Delhi. ${ }^{11}$ The TB-HIV case load was increased from $3.11 \%$ to $25.31 \%$ for period 2009 to 2011 , Similar upward trend was also reported from Bombay, ${ }^{12}$ but difference was high which could be due to lack of knowledge, attitude and practice about HIV-AIDS prevention in rural area.

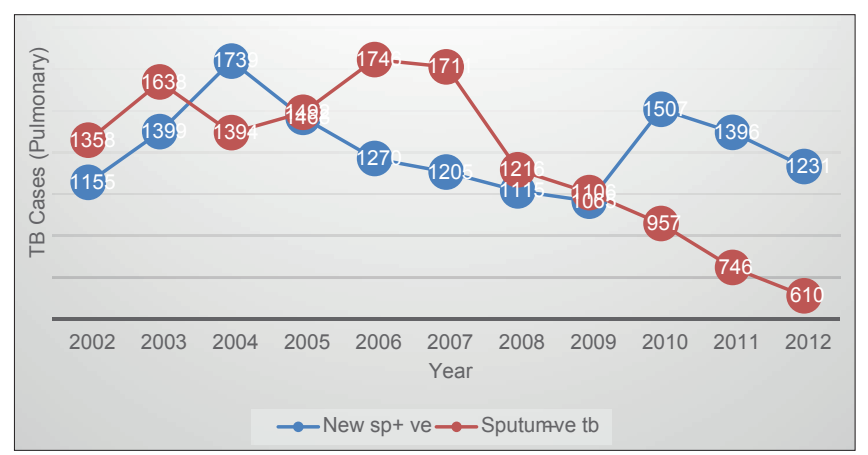

Figure 2: Trend of New sputum positive Pulmonary Tuberculosis. $\chi 2$ trend $=290.53, p<0.0001^{*}$

\begin{tabular}{|c|c|c|c|c|c|c|c|c|c|c|c|c|c|}
\hline Year & $\begin{array}{l}\text { Total } \\
\text { NSP } \\
\text { cases }\end{array}$ & $\begin{array}{c}\text { NSP } \\
\text { cases } \\
\text { cured@ }\end{array}$ & $\begin{array}{c}\text { NSP } \\
\text { cure } \\
\text { rate }(\%)\end{array}$ & $\begin{array}{c}\text { Sputum } \\
\text { conversion } \\
\text { cases }^{\#}\end{array}$ & $\begin{array}{c}\text { Rate } \\
(\%)\end{array}$ & $\begin{array}{c}\text { Treat. } \\
\text { Succes. } \\
\text { Cases* }\end{array}$ & $\begin{array}{c}\text { TSR } \\
(\%)\end{array}$ & $\begin{array}{c}\text { DF } \\
\text { cases }^{* *}\end{array}$ & $\begin{array}{c}\text { DF rate } \\
(\%)\end{array}$ & $\begin{array}{c}\text { TFL } \\
\text { cases }^{* * *}\end{array}$ & $\begin{array}{c}\text { TFL } \\
\text { rate }(\%)\end{array}$ & $\begin{array}{c}\text { DT } \\
\text { cases }^{* * * *}\end{array}$ & $\begin{array}{c}\text { DT rate } \\
(\%)\end{array}$ \\
\hline 2002 & 1271 & 1016 & 79.91 & 998 & 78.5 & 1096 & 86.23 & 96 & 7.5 & 80 & 6.2 & 79 & 6.2 \\
\hline 2003 & 1774 & 1458 & 82.18 & 1346 & 75.8 & 1545 & 87.0 & 106 & 5.9 & 87 & 4.9 & 123 & 6.9 \\
\hline 2004 & 2182 & 1865 & 85.47 & 1785 & 81.8 & 1946 & 89.1 & 89 & 4.0 & 81 & 3.7 & 147 & 6.7 \\
\hline 2005 & 1780 & 1549 & 87.02 & 1589 & 89.8 & 1608 & 90.3 & 61 & 3.5 & 67 & 3.7 & 111 & 6.2 \\
\hline 2006 & 1623 & 1404 & 86.50 & 1448 & 88.0 & 1442 & 88.8 & 67 & 4.5 & 31 & 1.9 & 114 & 7.0 \\
\hline 2007 & 1791 & 1501 & 83.80 & 1574 & 87.8 & 1542 & 86.0 & 155 & 8.6 & 41 & 2.2 & 94 & 5.2 \\
\hline 2008 & 1044 & 856 & 81.99 & 889 & 85.0 & 894 & 85.6 & 69 & 6.6 & 38 & 3.6 & 81 & 7.7 \\
\hline 2009 & 903 & 719 & 79.62 & 783 & 86.4 & 747 & 82.7 & 62 & 6.8 & 28 & 3.1 & 94 & 10.4 \\
\hline 2010 & 1423 & 1223 & 85.94 & 1304 & 91.6 & 1256 & 88.2 & 41 & 2.8 & 33 & 2.3 & 126 & 8.8 \\
\hline 2011 & 1175 & 986 & 83.91 & 1059 & 91.6 & 1013 & 86.2 & 45 & 3.8 & 27 & 2.2 & 117 & 9.9 \\
\hline 2012 & 1232 & 1049 & 85.14 & 1153 & 93.5 & 1076 & 87.3 & 58 & 4.7 & 27 & 2.1 & 98 & 7.9 \\
\hline
\end{tabular}

(NSP- New sputum + ve, TSR- Treatment success rate, DF-Defaulter, TFL-Treatment failure, DT-Death). ( ${ }^{(}: \chi^{2}$ trend $=64.63, p<0.0001^{*}, ": \chi^{2}$ trend $=119.91, p<0.0001 *$, ${ }^{*} \chi^{2}$ trend $=54.33, p<0.0001 * * * *: \chi^{2}$ trend $=109.01, p<0.00001^{*}, * * * \chi 2$ trend $=46.90, p<0.0001^{*}, * * * * \chi^{2}$ trend $\left.=21.13, p<0.0001^{*}\right)$ 


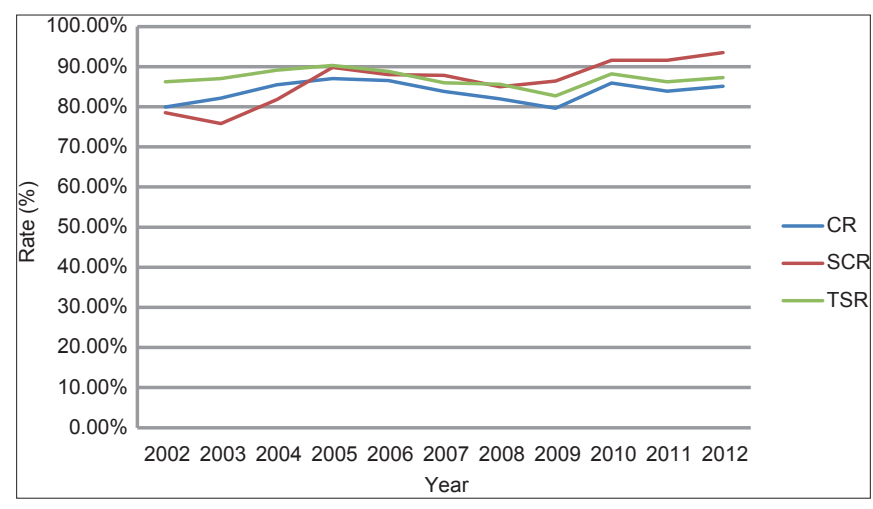

Figure 3.1: Cure rate, Sputum conversion rate and Treatment success rate. $(\mathrm{CR}=$ Cure rate, $\mathrm{SCR}=\mathrm{Sputum}$ conversion rate, $\mathrm{TSR}=$ Treatment success rate)

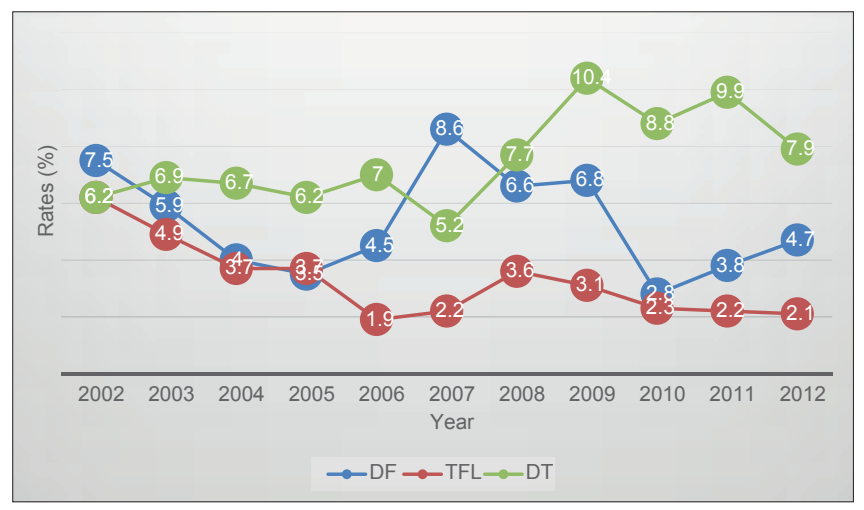

Figure 3.2: Defaulter rate, Treatment failure rate and Death rate. ( $\mathrm{DF}=$ Defaulter rate, $\mathrm{TFL}=$ Treatment failure rate, $\mathrm{DT}=$ Death rate)

Preponderance of male TB cases over female showed trend with time usually either upward or downward, similarity in findings were reported from Serbia. ${ }^{13}$ In present study, proportions of child TB cases increased for study period due to high prevalence of malnutrition, maternal TB and HIV infection, however proportions of child TB cases reported from Zambia ${ }^{14}$ were so high i.e. $135 \%$ to $69 \%$ and it indicates TB is still big problem either due to neglect child TB or poor implementation of TB control programme.

Proportions of pulmonary and extra pulmonary TB in males were higher than females and showed periodic fluctuation. A similar trend was observed in Serbia ${ }^{13}$ and South Delhi. ${ }^{11}$ Wang $\mathrm{J}^{15}$ also reported that women often remain undernotified by public health authority and undiagnosed female host may serve a potential source of latent infection. Among child TB, Proportion of pulmonary TB was higher than extra-pulmonary and showed downward and upward trend respectively, however very low proportion was observed from European ${ }^{16}$ area and difference was mainly due to quality health care services, standard of living and effective implementation of TB control activities.

In present study, proportion of NSP cases revealed increased trend from $41.3 \%$ to $50.5 \%$ for 2002 to 2012 , however exact opposite trend was reported from Dakshina Kannada district, Karnataka ${ }^{17}$ i.e. $50 \%$ to $42 \%$. Cure rate of NSP cases were ranged from $79.0 \%$ to $87 \%$ over study period and achieved goal of WHO-STOP TB Strategy, however rate was decreased from $85 \%$ to $79 \%$ in in Dakshina Kannada district, Karnataka. ${ }^{17}$ A similar downward trend was also reported from Sankhuwasava district of Nepal. ${ }^{18}$ Treatment success and sputum conversion rate was more than $86.2 \%$ and trend increased more than $90.3 \%$, similar findings also reported by Govt. of India, ${ }^{9}$ however it was reported low from in Sankhuwasava district of $\mathrm{Nepa}^{18}$ may be due to inadequate health infrastructure or poor finance for TB control. Defaulter rate decreased from $7.5 \%$ to $2.8 \%$ since 2002 to 2010 but again increased to $4.7 \%$ by 2012 due to change in behavior of cases as well as may be due to workload on peripheral health care staff, however trend of defaulter rate reported by Govt of India ${ }^{9}$ has been more than $6 \%$. Upward trend of defaulter rate has revealed from Dakshina Kannada district, Karnataka ${ }^{17}$ i.e. $6.8 \%$ to $10.4 \%$.

Our study revealed declining trend of Treatment failure rate from $6.2 \%$ to $2.1 \%$, similar trend also reported by Govt of India, ${ }^{9}$ Dakshina Kannada district, Karnataka ${ }^{17}$ and Bhojpur district of $\mathrm{Nepal}^{18}$ which could be due to case adherence.

Study reported upward trend of death rate from $6.2 \%$ to $10.4 \%$ for 2002 and remains above to $7.9 \%$ for 2012 , similar finding reported from Dakshina Kannada district, Karnataka. ${ }^{17}$ Death rate reported by Govt. of India ${ }^{9}$ was less than $5 \%$. However, it was decreased to less than 1\% in Sankhuwasava and Bhojpur district of $\mathrm{Nepal}^{18}$ and difference observed could be due to high prevalence if TB-HIV in western Maharashtra.

\section{CONCLUSION}

The outcome evaluation of RNTCP data from Satara district showing that burden of TB in rural area of western Maharashtra is still high. To reduce burden of TB, need to improve accessibility of health care services with main emphasis on public-private partnership, early case detection, adherence with treatment as well as improvement in standard of living. Developing countries with high burden of TB need to invest more resources in TB control strategy.

\section{REFERENCES}

1. World Health Organization. The global plan to stop Tuberculosis. Geneva 2010;WHO: 11-15.

2. Lal S. Text book of Community Medicine 2014; $4^{\text {th }}$ edi: CBS Publishers, New Delhi India. pp 435-442.

3. World Health Organization. Global tuberculosis control: surveillance, planning, finances. Geneva 2002;WHO/CDS/ TB/295. 
4. Directorate General Health Services. Revised National Tuberculosis Control Programme. Status Report, Central TB Division, Ministry of Health and Family Welfare; Govt of India 2013.

5. Donald PR and Van Helden PD. The global burden of tuberculosis combating drug resistance in difficult times. N Engl J Med 2009; 360:23.

6. Suryakantha $\mathrm{AH}$. Community Medicine with recent advances 2010.2 ${ }^{\text {nd }}$ edi; Jaypee publication, New Delhi; pp 330.

7. Park K. Text book of Preventive and Social Medicine 2013; $22^{\text {nd }}$ edi: Banarsidas Bhanot publishers, India. pp 166-168.

8. Directorate General Health Services. Revised National Tuberculosis Control Programme. Traning Module for Medical Practitioners. Central TB Division, Ministry of Health and Family Welfare; Govt of India 2006: pp 8-27.

9. Directorate General Health Services. TB India - Annual status report. Revised National Tuberculosis Control Programme. Central TB Division, Ministry of Health and Family Welfare; Govt of India 2012.

10. Crimi P. Epidemiological trend in tuberculosis in the Italian region of Liguria: impact of immigration and AIDS. Eur J Public Health 2005; 15(4):339-342.
11. Arora V and Gupta R. Trends of extra pulmonary tuberculosis under Revised National Tuberculosis Control Programme: a study from south Delhi. Indian J Tuberc 2006; 53:77-83.

12. Mohanty $\mathrm{K}$ and Basheer PM. Changing trend of HIV infection and Tuberculosis in Bombay area since 1988. Ind J Tuberc 1995; $42: 117$.

13. Dragica P. Tuberculosis incidence in Elderly in Serbia: a key trends in socio-economic transitgion. Croat Med J 2008; 49(6):807-812.

14. Kapata N. Trends in Childhood tuberculosis in Zambia. A cross sectional study. J Trop Pediatri 2013; 59(2):134-139.

15. Wang J. Gender difference in knowledge of tuberculosis and associated health care seeking behavioures: A cross sectional study in rural area of China. BMC Public Health 2008;8:354.

16. Sandgren S. Childhood tuberculosis in European economic area-2000-2009 Eurosurve. 2011, 16(12).

17. Ganesh Kumar S. Trend of tuberculosis cases under DOTS strategy in Dakshina Kannada district of Karnataka, India: Issues and Challenges. Iranian J Publ Health 2009; 38(4):72-76.

18. Shyam P. Need assessment for advocacy, communication and social mobilization for Tuberculosis control programme in community at Bhojpur, Sankhuwasabha and Saptari district, Nepal 2010; Academia Edu.

Authors Contribution:

RVM - Contributed to concept and study design VRM - Data collection and literature search PSG - Analysis of data and drafted the manuscript SVL - Editing and review of manuscript.

Source of Support: Nil, Conflict of Interest: None declared. 